\title{
METODOLOGIA EM VOGA NO CAMPO DE EMPREENDEDORISMO: EMPREGO DE MÉTODOS QUANTITATIVOS PARA O ESTUDO DAS CARACTERÍSTICAS INERENTES AOS EMPREENDEDORES
}

\author{
METHODOLOGY VOGA IN THE FIELD OF ENTREPRENEURSHIP: EMPLOYMENT \\ OF QUANTITATIVE METHODS FOR THE STUDY OF THE INHERENT \\ CHARACTERISTICS ENTREPRENEURS
}

\section{VOGA METODOLOGÍA EN EL ÁMBITO DE LA INICIATIVA EMPRESARIAL: EL EMPLEO DE MÉTODOS CUANTITATIVOS PARA EL ESTUDIO DE LOS EMPRESARIOS CARACTERÍSTICAS INHERENTES}

\section{Tayso Silva}

Mestre em Administração pela Universidade Estadual de Maringá - UEM

Estagiário Docente da Universidade Federal de Santa - UFSC

E-mail: taysosilva@ hotmail.com (Brasil)

Maurício Fernandes Pereira

Doutor em Engenharia de Produção pela Universidade Federal de Santa Catarina - UFSC

Professor da Universidade Federal de Santa Catarina - UFSC

E-mail: mfpcris@gmail.com (Brasil)

\author{
Alexandre Marino Costa \\ Doutor em Engenharia de Produção pela Universidade Federal de Santa Catarina - UFSC \\ E-mail: marinocad@gmail.com (Brasil) \\ Cristina Hinterlang \\ Mestre em Letras - Linguagem e Sociedade pela Universidade Estadual do Oeste do Paraná - \\ UNIOESTE \\ E-mail: cristinahinterlang@hotmail.com (Brasil)
}


Metodologia em Voga no Campo de Empreendedorismo: Emprego de Métodos Quantitativos para

O Estudo das Características Inerentes aos Empreendedores

\title{
METODOLOGIA EM VOGA NO CAMPO DE EMPREENDEDORISMO: EMPREGO DE MÉTODOS QUANTITATIVOS PARA O ESTUDO DAS CARACTERÍSTICAS INERENTES AOS EMPREENDEDORES
}

\section{RESUMO}

Objetivou-se investigar a forma como a metodologia quantitativa vem sendo empregada na pesquisa sobre o tema "características inerentes aos empreendedores". Especificamente, analisamos a produção brasileira exposta no Encontro Nacional da Anpad (EnANPAD) num período de 10 anos, desde 2003, ano da criação de um espaço específico para a produção em empreendedorismo, até 2012. Dentre os 279 artigos acerca de empreendedorismo publicados no EnANPAD nestes 10 anos foi analisada uma amostra intencional de 28 artigos. Em um primeiro momento foram analisados resumos, introduções e objetivos para a classificação dos temas e, posteriormente, procedeu-se à análise minuciosa dos métodos empregados nos estudos. No sentido de oferecer uma análise que proporcione um indicativo de como se caracterizam os estudos sobre empreendedorismo no Brasil em dias hodiernos, investigou-se o tema mais abordado em artigos da área de empreendedorismo para a avaliação do emprego da metodologia quantitativa, justificada também, como alvo desta investigação, por ser o principal método utilizado nos estudos sobre o tema.O estudo permitiu conhecer quais recursos metodológicos são adequados para investigar as características inerentes aos empreendedores e a forma como estes recursos foram utilizados. $\mathrm{O}$ nível de qualidade exigido para a publicação no EnANPAD colabora em afirmar sobre a viabilidade das estratégias de pesquisa expostas no presente estudo. Também há aqui uma contribuição para o delineamento do objeto de pesquisa no campo do empreendedorismo, especialmente no Brasil.

Palavras-chave: Empreendedorismo; Metodologia Quantitativa; EnANPAD.

\section{METHODOLOGY VOGA IN THE FIELD OF ENTREPRENEURSHIP: EMPLOYMENT OF QUANTITATIVE METHODS FOR THE STUDY OF THE INHERENT CHARACTERISTICS ENTREPRENEURS}

\begin{abstract}
This study aimed to investigate how the quantitative methodology has been employed in research on "the inherent characteristics of entrepreneurs." Specifically, we analyze the Brazilian production exposedat the National Meeting of Anpad( EnANPAD ) over 10 years, since 2003, year of the creationof aspecific space for production in entrepreneurship, by 2012. Among the 279 articles on entrepreneurship published in EnANPADin these 10 years,a purposive sample of 28 articles was analyzed. At first abstracts, introductions and objectives were analyzed for the classification of subjects and subsequently proceeded to the detailed analysis of the employedmethods in the studies.
\end{abstract}


Tayso Silva, Maurício Fernandes Pereira, Alexandre Marino Costa \& Cristina Hinterlang

In order to provide an analysis that indicates how to characterize the entrepreneurshipstudies on in Brazil in present, the moreaddressed issuein the field of entrepreneurship were investigated to evaluate the use of quantitative methodology, also justified, as target of this investigation, by being the main method used in the studies on the subject. The study allowsto identify methodological tools which are suitable to investigate the inherent characteristics of entrepreneurs and how these resources were used. The level of quality required for publication in EnANPAD collaborates to say about the viability of the search strategies outlined in this study. There is also a contribution to the delimitation of the object of research in the field of entrepreneurship, especially in Brazil.

Keywords: Entrepreneurship; Quantitative Methodology; EnANPAD.

\section{VOGA METODOLOGÍA EN EL ÁMBITO DE LA INICIATIVA EMPRESARIAL: EL EMPLEO DE MÉTODOS CUANTITATIVOS PARA EL ESTUDIO DE LOS EMPRESARIOS CARACTERÍSTICAS INHERENTES}

\section{RESUMEN}

Este estudio tuvo como objetivo investigar la forma en la metodología cuantitativa se ha empleado en la investigación sobre " las características inherentes de los empresarios . " En concreto , se analiza la producción brasileña expuesta en la Reunión Nacional de la ANPAD ( EnANPAD ) durante 10 años, desde 2003 , la creación de un espacio específico para la producción en el espíritu empresarial para el año 2012 . Entre los 279 artículos sobre el espíritu empresarial publicados en EnANPAD estos 10 años se analizó una muestra intencionada de 28 artículos . En primera resúmenes, se analizaron las presentaciones y los objetivos para la clasificación de los sujetos y procedieron al análisis detallado de los métodos empleados en los estudios posteriormente . A fin de proporcionar un análisis que proporciona una indicación de cómo caracterizar los estudios sobre el espíritu empresarial en Brasil en día de hoy en día , investigó la cuestión concreta de los artículos en el campo de la iniciativa empresarial para evaluar el uso de la metodología cuantitativa también justificados objetivo de esta investigación, es el principal método utilizado en los estudios sobre el estudio tema.O ayudó a identificar las herramientas metodológicas que son adecuados para investigar las características empresariales inherentes y cómo se usaron esos fondos. El nivel de calidad requerido para su publicación en EnANPAD colabora para decir acerca de la viabilidad de las estrategias de búsqueda descritas en este estudio. Aquí también hay una contribución al diseño del objeto de la investigación en el campo de la iniciativa empresarial, especialmente en Brasil .

Palabras-clave: Emprendimiento; Cuantitativo Metodología; EnANPAD . 
Metodologia em Voga no Campo de Empreendedorismo: Emprego de Métodos Quantitativos para

O Estudo das Características Inerentes aos Empreendedores

\section{INTRODUÇÃO}

Pela relativa incipiência do empreendedorismo enquanto objeto de estudo e disciplina em administração, ainda não existe um consenso pleno entre os principais estudiosos da área acerca de suas fronteiras. Bruyat e Julien (2000) mencionam que - embora a importância do campo do empreendedorismo seja reconhecida e vários pesquisadores no mundo voltaram-se à produção nesta área - ainda não existe concordância em qual o objeto de pesquisa específico neste campo científico.

Em um levantamento realizado por Souza (2005) junto a estudos de importantes autores (Schumpeter, McCleland, Filion, Degen, Drucker, Dutra, Longnecker, Mintzberg, entre outros) revelou o consenso geral apenas em o empreendedorismo estar relacionado à inovação, embora possam haver outros autores que não compartilham desta opinião, todos os outros assuntos abordados no empreendedorismo, como a criação de empresas, pequenas empresas, intraempreendedorismo, são motivo de bifurcação conceitual. Estas divergências sobre quais são os assuntos pertinentes ao empreendedorismo, aliadas às diferentes perspectivas oferecidas por diferentes autores podem não consentir em uma definição comum, mas instigam à busca de um aprofundamento no estudo acerca do empreendedorismo. A subjetividade da análise dos fatores considerados inerentes ao estudo do empreendedorismo dificulta a produção teórica na área, gerando inclusive divergências em aspectos como consideração do empreendedorismo social, a sua existência em uma firma já estabelecida, ou somente em novos negócios, o conceito de intraempreendedorismo ou empreendedorismo coorporativo, ou se o empreendedorismo abrange imitações e é restrito à inovação.

Estudos acerca do empreendedorismo têm se expandido mesmo com a reconhecida falta de consenso sobre a delimitação de seu campo (FILION, 1997). No sentido de oferecer uma análise que proporcione um indicativo de consenso nos estudos acerca de empreendedorismo, buscou-se encontrar seu tema de pesquisa mais fortalecido em números de artigos que dedicam estudos no principal evento científico de administração do Brasil, sendo encontrado o tema "Características inerentes aos empreendedores".Com a definição deste tema para a análise, diagnosticou-se, entre o total de61 artigos publicados,qual foia abordagem metodológica mais utilizadaem tais artigos. Os dados da tabela 1 mostram que a metodologia mais usada foi a quantitativa. Deve-se salientar que menos de 6,6\% dos artigos apresentados consistemensaios teóricos, comprovando um dado mais específico quanto à tendência das exigências para publicações. 
Tayso Silva, Maurício Fernandes Pereira, Alexandre Marino Costa \& Cristina Hinterlang

Tabela 1 - Distribuição da metodologia usada

\begin{tabular}{|l|c|}
\hline \multicolumn{1}{|c|}{ TIPO DE ABORDAGEM METODOLÓGICA } & QUANTIDADE \\
\hline Quantitativa & 28 \\
\hline Qualitativa & 22 \\
\hline Quantitativa e Qualitativa & 7 \\
\hline Ensaio Teórico & 4 \\
\hline Total & 61 \\
\hline
\end{tabular}

Fonte: (ANPAD, on line, 2013a)

A escolha do evento EnAnpad como foco deste estudo decorre sobretudo do seu reconhecimento pela comunidade científica como o principal evento da Administração no país. Conforme as informações da ANPAD (online, 2013b), este é o maior evento da comunidade científica de administração no Brasil, com uma média de três mil submissões de artigos nos últimos três anos, dos quais cerca de oitocentos foram aceites para apresentação.

As pesquisas científicas devem ser planejadas e executadas de acordo com normas requeridas por cada método de investigação. Em uma classificação ampla considera-se a existência de dois grandes métodos: o quantitativo e o qualitativo, diferenciando-se entre si não só pela sistemática de funcionamento, mas, sobretudo, pela abordagem ao problema. Desta forma, é necessário que o método seja apropriado ao tipo de estudo que se deseja realizar (RICHARDSON, 1999). Justamente neste sentido, o presente estudo objetivou investigar a forma como a metodologia quantitativa vem sendo empregada na pesquisa sobre as características inerentes aos empreendedores, mais especificamente na produção brasileira exposta no Encontro Nacional da Anpad.

O problema de pesquisa referente a tal objetivo pode ser melhor descrito pela busca do conhecimento sobre como uma determinada metodologia vem sendo empregada em determinado tema. Assim, há o interesse em avaliar as estratégias de uso da metodologia quantitativa para investigar as características inerentes aos empreendedores por justamente esta representar a principal modalidade de pesquisa quando se trata desta área do empreendedorismo no universo 
Metodologia em Voga no Campo de Empreendedorismo: Emprego de Métodos Quantitativos para

O Estudo das Características Inerentes aos Empreendedores

avaliado, o que também indica a adequação de métodos quantitativos ao objeto de estudo citado, contribuindo, mais uma vez para o estímulo ao interesse do presente objetivo.

O contexto brasileiro também é relevante. O GEM - Global Entrepreneurship Monitoriniciou em 1999 uma avaliação anual dos níveis de atividade empreendedora em diferentes países por meio de uma parceria entre a London Business School e o BabsonCollege. Atualmente, é o maior estudo do mundo contínuo sobre a dinâmica empreendedora (GEM, 2013). Aqui, o GEM realiza a pesquisa anualmente por meio de uma parceria entre o Sebraee o Instituto Brasileiro da Qualidade e Produtividade (IBQP), revelando o Brasil comoo terceiro país com o maior número de pessoas envolvidas em um negócio próprio ou na criação de um, atrás apenas da China e dos EUA em uma lista de 54 países, totalizando 27 milhões de pessoas (SEBRAE, online, 2012). Tais informações contribuem para reforçar a importância dos estudos sobre empreendedorismo no Brasil.

Como principais resultados, pode-se, além de analisar o uso de estratégias de pesquisa e instrumentos empregados em estudos sobre as características inerentes aos empreendedores, diagnosticar quais fatores têm sido abordados neste tema. Foram analisadas escalas, técnicas de triangulação, pré-teste, tratamentos estatísticos, abordagem paradigmática, sistemas de amostragem e, incluindo, diagnosticou-se as características dos empreendedores usualmente investigadas nestes estudos apresentados nesta recente década da história do EnANPAD.

Entre os resultados expostos também consta que os questionários foram instrumentos usados em todos os estudos analisados, sendo diagnosticadas, entre aqueles que não foram empregados pessoalmente, taxas de devolução superiores às habituais. Esta é mais uma contribuição da análise das estratégias de pesquisa que, ao ser organizada por meio deste estudo, permite novas sugestões para otimizar a eficiência das pesquisas de campo. Ainda será apresentada nos resultados deste estudo, com relação aos critérios de confiabilidade e validade dos artigos avaliados, a carência de pré-teste dos instrumentos e principalmente de triangulação de informações, sendo que apenas um artigo alegou o emprego de tal estratégia.Entretanto, observa-se a sofisticação e riqueza em diversidade dos tratamentos estatísticos, empregados pela maior parte dos estudos, contribuindo para a importância dos mesmos com relação à validade e confiabilidade do conhecimento científico.

Este artigobuscou conhecer quais recursos metodológicos são adequados para investigar as características inerentes aos empreendedores e a forma como estes recursos foram utilizados. O nível de qualidade exigido para a publicação no EnANPAD colabora em afirmar sobre a viabilidade das estratégias de pesquisa expostas no presente estudo. Também há aqui uma contribuição para delinear qual é o objeto de pesquisa no campo do empreendedorismo, especialmente no Brasil. 
Tayso Silva, Maurício Fernandes Pereira, Alexandre Marino Costa \& Cristina Hinterlang

\section{REFERENCIAL TEÓRICO}

A preparação para a análise e discussão dos resultados passou pela revisão de autores que abordaram previamente sobre características do empreendedor e sobre a o emprego da metodologia quantitativa para investigar temas da administração. Com base em tais autores pode-se estabelecer a base necessária para a construção do aparato de pesquisa necessário à consecução do objetivo de estudo proposto.

\subsection{CARACTERÍSTICAS DO EMPREENDEDOR}

Os empreendedores e as empresas empreendedoras variam largamente em suas características, assim como o ambiente no qual eles atuam interfere e responde diretamente às diversas ações empreendedoras. Mais especificamente com relação aos indivíduos empreendedores, estes diferem em importantes aspectos de não-empreendedores e acredita-se que tais diferenças são encontradas na personalidade e no conhecimento do empreendedor (GARTNER, 1985).Para compreender porque determinados indivíduos se tornam empreendedores e outros não, Sarasvathy (2004), analisou a distribuição de potencial em se tornarem empreendedores, considerando que alguns indivíduos serão empreendedores independentemente do contexto em que estão inseridos, outros não se transformarão empreendedores em qualquer contexto possível, mas a principal parcela consistirá nos indivíduos que se tornarão empreendedores sob determinados contextos e outros não. Assim, para identificar tais indivíduos é necessário considerar parâmetros-chave da variação entre as características dos empreendedores para então examinar porque as pessoas que apresentam essas variações optam por empreender ou não.

Pelo fato de provirem de experiências educacionais, situações familiares e vivências profissionais variadas (HISRICH; PETERS, 2004), a capacidade de inovar é reconhecida como uma das habilidades do empreendedor. O estudo realizado por Souza (2005) procurou identificar características associadas ao conceito de empreendedor. Para tanto, foram analisados o conteúdo de textos sobre empreendedorismo sendo que os dados afirmaram que os empreendedores são pessoas envolvidas no processo de inovação. Além disso, a maior parte dos pesquisadores concorda que para empreender é necessário aceitar os riscos inerentes ao novo negócio, buscar oportunidades e apresentar capacidade criativa.

Com relação à busca de oportunidades, o empreendedor é analisado como um agente reflexivo engajado em uma ação proposital na qual ele desenvolve e descobre a oportunidade. Além 
Metodologia em Voga no Campo de Empreendedorismo: Emprego de Métodos Quantitativos para

O Estudo das Características Inerentes aos Empreendedores

de estar atento às oportunidades estáticas, ele dinamicamente gera novas oportunidades e novos negócios por meio de ações embasadas em interpretações subjetivas, assim, o empreendedor constrói negócios, parcialmente, utilizando sua habilidade de influenciar o ambiente socioeconômico em seu favor (SARASON; DEAN; DILLARD, 2006), podendo ele organizar e reorganizar mecanismos socioeconômicos objetivando transformar situações e recursos para proveito prático (HISRICH; PETERS, 2004), influenciando voluntária e involuntariamente o contexto.A pró-atividade está relacionada às características empreendedoras. Um empreendedor mais proativo possui mais predisposição para abrir um novo negócio. Analisar como as pessoas proativas influenciam seus ambientes pode ser uma variável importante para entender o comportamento empreendedor (BECHERER; MAURER, 1999).

Conforme Hisrich e Peters (2004), a aceitação de riscos está em praticamente todas as definições recentes de empreendedor. Faz parte do processo empresarial assumir riscos, sejam eles financeiros, sociais ou psicológicos. O foco dos estudos sobre aceitação de riscos se concentra no componente de uma propensão geral para riscos, entretanto, como não foram determinadas relações causais conclusivas, ainda não foi empiricamente estabelecido que uma propensão para riscos seja uma característica distintiva dos empreendedores.

Empreendedores também apresentam um maior desejo de independência, quando comparados ao restante da população, levando-os a tentarem construir seu próprio negócio. Indivíduos que apresentam um forte desejo de independência são mais propensos a explorar oportunidades empreendedoras porque a atividade empreendedora exige tomada de decisões pessoais ao invés de seguir o julgamento de terceiros. Contudo, o desejo de independência pode influenciar negativamente a exploração de uma oportunidade empreendedora caso ele atrapalhe a formação de importantes laços junto a consumidores, fornecedores, empregados ou investidores (SHANE, 2003).

Para Hisrich e Peters (2004), o ambiente familiar na infância exerce influência na formação de indivíduos empreendedores. Há evidências de que os empreendedores tendem a ter pais também empreendedores. Ter pais que trabalham por conta própria propicia uma inspiração para o empreendedor, pois a natureza independente e a flexibilidade do trabalho autônomo exemplificadas são mais facilmente absorvidas em idade precoce. O relacionamento dos pais com a criança talvez seja o aspecto mais importante do ambiente familiar na infância para o estabelecimento do desejo pela atividade empresarial em um indivíduo. Os pais dos empreendedores podem demonstrar apoio e estimular a independência, a conquista e a responsabilidade. 
Tayso Silva, Maurício Fernandes Pereira, Alexandre Marino Costa \& Cristina Hinterlang

A necessidade de realização também motiva as pessoas a serem empreendedoras. Conforme Shane (2003) e Hisrich e Peters (2004), a necessidade de realização melhora a possibilidade do indivíduo tornar-se empreendedor considerando que este irá ter como alvo a consecução de seus objetivos profissionais.

\subsection{A METODOLOGIA QUANTITATIVA NA ADMINISTRAÇÃO}

Conforme Bryman (1988), muito do conhecimento existente sobre os fundamentos da metodologia quantitativa deriva de escritores que seguem a tradição das pesquisas qualitativas. Entretanto, isto não necessariamente deprecia o conhecimento existente sobre o tema dado o entendimento muito claro de suas características essenciais, tipicamente exemplificadas por experimentos e surveys. A abordagem quantitativa possibilita abrangência para a pesquisa, e conforme Richardson (1999), caracteriza-se pelo emprego da quantificação tanto nos instrumentos de coleta de informações quanto no tratamento dos dados por meio de técnicas estatísticas, visando, em princípio, a precisão dos resultados e, consequentemente, uma margem de segurança quanto às inferências.

Os defensores da abordagem qualitativa alegam a inadequação dos métodos quantitativos por estes serem próprios das ciências naturais, sendo inapropriado utilizá-los em investigações sociais (BRYMAN, 1988; RICHARDSON, 1999). Parte desta inadequação atribuída decorre-se das características inerentemente positivistas da pesquisa qualitativa. Além do positivismo considerar válido o emprego das técnicas de pesquisa das ciências naturais às ciências sociais, os pesquisadores positivistas têm consentido que: a) apenas os fenômenos observáveis são passíveis de constituírem conhecimento teorizado; b) o conhecimento científico provêm da acumulação de fatos verificáveis; c) o conhecimento científico é tido como base da qual emergem hipóteses para a investigação empírica; d) os cientistas devem ser purificados de valores que possam interferir na objetividade de suas análises (BRYMAN, 1988).

Uma diferenciação observada nos estudos da área de administração, inclusive certificada nos artigos hora avaliados, é o fato dos experimentos neste campo da ciência social não ocorrerem em laboratórios, assim como ocorrem nas ciências naturais. Os experimentos em laboratórios, conforme exposto por Bryman (1988), podem desconsiderar as implicações contextuais, levando a resultados divergentes do que ocorreria no ambiente organizacional.

Entretanto, observa-se uma corrente paradigmática nestes estudos que, assim como nas demais áreas da administração, tende a buscar uma simplificação dos fenômenos. Considerando-se 
Metodologia em Voga no Campo de Empreendedorismo: Emprego de Métodos Quantitativos para

O Estudo das Características Inerentes aos Empreendedores

a classificação de Burrel e Morgan (1979), a qual considera quatro correntes paradigmáticas que variam em um eixo que classifica os paradigmas indo do subjetivo ao objetivo e outro eixo que varia entre a sociologia da mudança radical e a sociologia da regulação. Conforme os autores, o paradigma funcionalista (pertinente ao quadrante situado nas extremidades "objetivo" e "sociologia da regulação" dos eixos) é uma corrente dominante nos estudos organizacionais.

\section{MÉTODO}

Com relação à classificação, trata-se de uma pesquisa documental realizada junto aos anais do Enanpad, pois, conforme Fachin (2003), a busca de qualquer informação registrada de forma oral, escrita ou em imagem corresponde à pesquisa documental, consistindo na coleta, classificação, seleção difusa e as técnicas e métodos que facilitam a sua busca e a sua identificação.

Para a seleção dos trabalhos a serem considerados na presente avaliação, optou-se pelos 279 artigos levantados nos temas de interesse do EnAnpad constantes na tabela 2: 
Tayso Silva, Maurício Fernandes Pereira, Alexandre Marino Costa \& Cristina Hinterlang

Tabela 2 - Relação de temas de interesse do EnAnpad compreendidos no estudo

\begin{tabular}{|c|c|c|c|c|c|}
\hline ANO & $\mathbf{N}^{\mathbf{0}}$ & TEMA DE INTERESSE & $\mathbf{N}^{\mathbf{0}}$ & TEMA DE INTERESSE & TOTAL \\
\hline 2012 & 10 & Estratégia e Empreendedorismo & 11 & Inovação e Empreendedorismo & 21 \\
\hline 2011 & 11 & Estratégia e Empreendedorismo & 7 & Inovação e Empreendedorismo & 18 \\
\hline 2010 & 9 & $\begin{array}{c}\text { Estratégia, Empreendedorismo e } \\
\text { Desenvolvimento }\end{array}$ & 11 & Inovação e Empreendedorismo & 20 \\
\hline 2009 & 12 & $\begin{array}{c}\text { Estratégia, Empreendedorismo e } \\
\text { Desenvolvimento }\end{array}$ & 9 & Inovação, Empreendedorismo e Redes & 21 \\
\hline 2008 & 25 & $\begin{array}{c}\text { Empreendedorismo e } \\
\text { Comportamento Empreendedor }\end{array}$ & 12 & $\begin{array}{c}\text { Empreendedorismo e Negócios } \\
\text { Inovadores }\end{array}$ & 37 \\
\hline 2007 & 21 & $\begin{array}{c}\text { Empreendedorismo e } \\
\text { Comportamento Empreendedor }\end{array}$ & 13 & $\begin{array}{c}\text { Empreendedorismo e Negócios } \\
\text { Inovadores }\end{array}$ & 34 \\
\hline 2006 & 23 & $\begin{array}{c}\text { Empreendedorismo e } \\
\text { Comportamento Empreendedor }\end{array}$ & 12 & $\begin{array}{c}\text { Empreendedorismo e Negócios } \\
\text { Inovadores }\end{array}$ & 35 \\
\hline 2005 & 22 & $\begin{array}{c}\text { Empreendedorismo e } \\
\text { Comportamento Empreendedor }\end{array}$ & 13 & $\begin{array}{c}\text { Empreendedorismo e Negócios } \\
\text { Inovadores }\end{array}$ & 35 \\
\hline 2004 & 33 & $\begin{array}{c}\text { Empreendedorismo e } \\
\text { Comportamento Empreendedor }\end{array}$ & & & 33 \\
\hline 2003 & 25 & $\begin{array}{c}\text { Empreendedorismo e } \\
\text { Comportamento Empreendedor }\end{array}$ & & & 25 \\
\hline Total & 191 & & 88 & & 279 \\
\hline
\end{tabular}

Fonte: (ANPAD, on line, 2013a)

As Divisões Acadêmicas que abarcam os artigos publicados no EnAnpad são delimitadas por meio de Temas de Interesse Científico, correspondentes amplamente às distintas esferas de que é constituída a administração. Tais Divisões Acadêmicas acompanham o dinamismo inerente às discussões científicas (ANPAD, online, 2012), acarretando, desta forma, o surgimento, extinção ou alterações nas nomenclaturas de temas de interesses e divisões acadêmicas do evento. No caso dos estudos acerca do empreendedorismo, estes ganharam um espaço próprio no ano de 2003, conforme pode ser observado na tabela 2, justificando a delimitação temporal deste estudo que considerará os anais do evento daquele ano em diante. Assim, o presente estudo avalia os 10 anos do espaço 
Metodologia em Voga no Campo de Empreendedorismo: Emprego de Métodos Quantitativos para O Estudo das Características Inerentes aos Empreendedores

específico para a produção sobre empreendedorismo no EnAnpad.A partir de 2005 surgiu na área Gestão de Ciência, Tecnologia e Inovação o tema Empreendedorismo e Negócios Inovadores, agrupando mais um conjunto de artigos à presente análise.

\subsection{AMOSTRA}

A Tabela 3 apresenta grupos temáticos dos 279 artigos publicados no EnAnpad entre 2003 e 2012 acerca de empreendedorismo, demonstrando a principal vertente temática a qual se refere a características inerentes aos empreendedores, totalizando 61 artigos.

Adotou-se, para classificação em grupos temáticos, a verificação de evidências no resumo dos artigos e, nos casos destes serem insuficientes, ampliou-se a verificação ao artigo completo.

Tabela 3 - Principais temas acerca do empreendedorismo publicados no EnAnpad

\begin{tabular}{|c|c|c|c|c|c|c|c|c|c|c|c|}
\hline Tema & 03 & 04 & 05 & 06 & 07 & 08 & 09 & 10 & 11 & 12 & $\mathbf{T}$ \\
\hline $\begin{array}{l}\text { Características inerentes aos } \\
\text { empreendedores }\end{array}$ & 6 & 7 & 10 & 9 & 8 & 5 & 2 & 3 & 5 & 6 & 61 \\
\hline $\begin{array}{l}\text { Incubadoras e sistema de apoio ao } \\
\text { empreendedorismo }\end{array}$ & 2 & 3 & 4 & 3 & 3 & 1 & 1 & 2 & & 3 & 22 \\
\hline Tecnologia e inovação & 1 & 4 & 3 & 2 & 2 & 5 & 3 & 3 & 2 & 1 & 26 \\
\hline Sistema de redes & 1 & 3 & 2 & 1 & 3 & 1 & 4 & 1 & & 1 & 17 \\
\hline Pequenos negócios & 2 & 4 & 3 & 3 & 4 & 5 & 2 & 1 & & & 24 \\
\hline Educação empreendedora & 2 & 3 & & 1 & & 1 & & & & 1 & 8 \\
\hline Empreendedorismo e sociedade & 1 & & 2 & 2 & 1 & 1 & 2 & 1 & 2 & & 12 \\
\hline $\begin{array}{l}\text { Capital de risco e financiamento de } \\
\text { pequenos negócios }\end{array}$ & 2 & & 1 & 1 & & & & 1 & 1 & 1 & 7 \\
\hline Franquias & 2 & & & 2 & & 1 & & & 1 & & 6 \\
\hline Criação negócios & 1 & 2 & 1 & 1 & 2 & 1 & & 2 & 1 & 1 & 12 \\
\hline
\end{tabular}


Tayso Silva, Maurício Fernandes Pereira, Alexandre Marino Costa \& Cristina Hinterlang

\begin{tabular}{|l|c|c|c|c|c|c|c|c|c|c|c|}
\hline Empresas familiares & 1 & & & 2 & & 1 & & & & 1 & 5 \\
\hline Conceitos de empreendedorismo & & 3 & 1 & 3 & 2 & 2 & 3 & 1 & 1 & 1 & 17 \\
\hline Criatividade & & 1 & 1 & & 2 & 1 & & 1 & 1 & & 7 \\
\hline Intraempreendedorismo & 1 & & 1 & 1 & 3 & 5 & & 1 & 1 & 2 & 15 \\
\hline Desenvolvimento econômico & & & & 2 & & 1 & 1 & 1 & 1 & 1 & 7 \\
\hline Empreendedorismo feminino & 1 & 1 & & 1 & 2 & 1 & & & & 2 & 8 \\
\hline Outros & 2 & 2 & 6 & 1 & 2 & 5 & 3 & 2 & 2 & & 25 \\
\hline Total & 25 & 33 & 35 & 35 & 34 & 37 & 21 & 20 & 18 & 21 & 27 \\
\hline
\end{tabular}

Fonte: (ANPAD, on line, 2013a)

Houve casos nos quais o artigo poderia classificar-se em mais de uma categoria como no artigo de Marchelli e Corcetti (2004) intitulado: "Gestão da inovação na incubadora de base tecnológica do INATEL”, que poderia ser enquadrado tanto no tema de Incubadoras quanto em Tecnologia e Inovação. Assim, optou-se por ter como critério decisório o foco do objetivo do estudo que, neste caso, tratava claramente do processo incubador de empresas no Brasil.

Optou-se por investigar a utilização da metodologia, especificamente, no tema mais frequente (Características inerentes aos empreendedores) por este refletir o maior consenso sobre o objeto de análise nos estudos sobre empreendedorismo no universo considerado. A eleição de um único tema para análise também permite o aprofundamento sobre a adequação de ferramentas de pesquisa para estudar um assunto específico.

A relação de temas elencados na tabela 3 reflete, parcialmente, a relação proposta por Welsch (1992) na qual constam, originalmente, 27 temas. Os temas encontrados com baixa incidência (até três artigos no período de 2003 a 2012) foram agrupados na categoria "Outros" juntamente com aqueles cuja identificação temática não fora possível categorizá-la. 
Metodologia em Voga no Campo de Empreendedorismo: Emprego de Métodos Quantitativos para

O Estudo das Características Inerentes aos Empreendedores

\section{ANÁLISE E DISCUSSÃO DOS RESULTADOS}

As características inerentes ao empreendedor mencionadas anteriormente estão longe de serem exaustivas, entretanto, vale ressaltar que o tema tem sido a principal vertente nos estudos sobre empreendedorismo apresentados no maior evento de estudos da administração no Brasil. Por hora, faz-se do interesse da presente pesquisa demonstrar a maneira como tais estudos vêm sendo tratados metodologicamente, sobretudo por meio da abordagem quantitativa, a qual foi hora diagnosticada como a mais frequente nos artigos acerca do tema em questão.

Com a utilização da abordagem metodológica quantitativa pode-se observar sua aplicabilidade para investigação de diversos fatores relacionados ao tema em questão. A análise dos 28 artigos publicados com este perfil, tal como comentado por meio da tabela 1, apresentou discussões quantitativas sobre os seguintes fatores relacionados às características inerentes aos empreendedores: poder, ação estratégica, capacidade de persuasão, desejo de independência, autoconfiança, idade, sexo, estado civil, número de filhos, capacidade de assumir riscos, orientação para busca de oportunidade, iniciativa, capacidade de planejamento, persistência, redes de contatos, intenção empreendedora, características emocionais, atitudes, lócus de controle, experiência, missão, traços psicológicos, temperamento, pensamento analítico, variáveis culturais, potencial empreendedor, entre outros fatores referentes às características inerentes aos empreendedores que puderam ser investigados adequadamente sob a metodologia quantitativa.

\subsection{CARACTERÍSTICAS PARADIGMÁTICAS}

Utilizando-se da classificação paradigmática apresentada por Burrel e Morgan (1979), verificou-se que $100 \%$ dos artigos investigados foram produzidos seguindo o paradigma funcionalista. Esta é uma informação de suma importância tendo em conta que "o paradigma é invisível para quem sofre seus efeitos mas é o que há de mais poderoso sobre as suas idéias”. Com estas palavras Morin (2002, p. 31) chama atenção para a importância do problema da paradigmatologia. O autor considera o paradigma uma relação muito forte, podendo ser de conjunção ou disjunção, aparentemente de natureza lógica entre alguns conceitos centrais. Tal tipo de relação determina o curso de todas as teorias e discursos controlados pelo paradigma. Corroborando, para Bryman (1988, p. 4), o paradigma: 
Tayso Silva, Maurício Fernandes Pereira, Alexandre Marino Costa \& Cristina Hinterlang

É um conjunto de crenças e ditados que para cientistas em uma determinada disciplina influenciam o que pode ser estudado, como a pesquisa pode ser dada, como os resultados podem ser interpretados, e assim por diante.

A tradição do paradigma dominante dos estudos das organizações foi desenvolvida por meio de metáforas suportadas pelo paradigma funcionalista e seus pressupostos, ocasionando o desenvolvimento de teorias baseadas em fundamentos praticamente indiscutíveis até os anos 1980 (SERVA; DIAS; ALPERSTEDT, 2010).O funcionalismo tem seu foco em entender a natureza dos fenômenos culturais puramente ditos, ou seja, livres de manipulações especulativas, busca tratar os fatos de forma indutiva para que se possam produzir generalizações válidas. Aceita-se a existência de objetos isolados dos quais partem qualquer análise cultural profunda. Um objeto de estudo, como uma instituição, tem uma estrutura válida universalmente para todos os tipos de unidades (MALINOWSKI, 1970).

Se por um lado apresentam-se deficiências com relação ao paradigma dominante da forma como é empregado nos estudos da área, por outro pode-se considerar, de certa forma, os benefícios da sinergia engendrada quando a maior parte dos autores seguem a mesma corrente paradigmática. Os riscos de uma impropriedade epistemológica são diminuídos quando é possível confrontar diversos conhecimentos produzidos sob uma mesma lente.

Há correntes que apontam desvantagens do funcionalismo. Para Morin (2002), a essência do paradigma da simplificação, condutor da ciência clássica, é o princípio da disjunção e da redução. Assim, determina-se um raciocínio que separa as categorias, as disciplinas, o objeto de seu meio e assim por diante. Atua por meio da redução levando as operações comandadas por este paradigma a serem fundamentalmente unidimensionais e, sobretudo, disjuntivas e redutoras. O paradigma da simplificação só permite enxergar unidades e diversidades abstratas, ocultando a diversidade na unidade ou a unidade na diversidade.

A consideração de outras abordagens paradigmáticas tende a enriquecer as contribuições teóricas acerca das características inerentes aos empreendedores, por exemplo por meio do paradigma da complexidade. O trabalho de Heinz Von Foester em 1956 apresenta, pela primeira vez, características do Paradigma da Complexidade como a causalidade circular, consideração do acaso e auto-referência, na área da biologia, posteriormente sendo empregado na área humana (SERVA, 1992), a qual é a portadora da "maior complexidade que podemos conceber até agora". Ela é complexa em comparação a um universo biológico do qual ela faz parte que também é complexo. Neste entendimento, a complexidade diz respeito ao humano da mesma maneira que o faz do biológico, não levando tal problemática ao reducionismo. Pelo contrário, traz complexidade (MORIN, 1982, p. 223). Por se tratar especificamente de características do indivíduo, o paradigma 
Metodologia em Voga no Campo de Empreendedorismo: Emprego de Métodos Quantitativos para

O Estudo das Características Inerentes aos Empreendedores

da complexidade constitui uma alternativa conveniente para tratar do tema em questão, também de umaforma a complementar a literatura existente.

\subsection{TÉCNICAS DE AMOSTRAGEM}

Uma das preocupações da pesquisa quantitativa é garantir a generalização de seus estudos. Entre os pesquisadores que atuam sobre tal metodologia, esta preocupação reflete-se na atenção atribuída à amostragem, mais especificamente no sentido de garantir a representatividade das amostras. O que tem se encontrado nos livros de metodologia sobre isto é a preferência da seleção de amostras de forma aleatória sob a alegação de que por meio destas legitima-se a generalização para uma ampla população da qual a amostra é representativa (BRYMAN, 1988). Entre os trabalhos avaliados, 60,7\% especificaram o modelo de amostragem empregado. Estes distribuem-se conforme a tabela 4 :

Tabela 4 - Formas de amostragem empregadas

\begin{tabular}{|l|c|}
\hline \multicolumn{1}{|c|}{ Amostragem } & Proporção \\
\hline Aleatória & $47,1 \%$ \\
\hline Por conveniência & $35,3 \%$ \\
\hline Estratificada & $17,6 \%$ \\
\hline Total & $100 \%$ \\
\hline
\end{tabular}

Fonte: (ANPAD, on line, 2013a)

O modelo de amostragem menos utilizado, a Estratificada, poderia ser mais privilegiado nos estudos, tendo em conta sua eficiência e representatividade diferenciadas. A estratificação proporcional é mais recomendável por fornecer uma amostra mais representativa da população(COSTA NETO, 2002), devendo a amostra ser uma fração da população-alvo selecionada considerando critérios para garantir sua representatividade (COOPER; SCHINDLER, 2003).Preocupando-se com a representatividadeda amostra, pode ser adotado o modelo de amostragem estratificada proporcional que permite diminuir o tamanho da amostra e ainda assim 
Tayso Silva, Maurício Fernandes Pereira, Alexandre Marino Costa \& Cristina Hinterlang

permanecer representativa (COSTA NETO, 2002). É possível utilizar o processo de amostragem estratificada em populações heterogêneas nas quais se pode distinguir sub-populações que se diferenciem por uma ou mais características entre si, denominadas estratos, sendo que as variáveis de estratificação podem ser quaisquer atributos que revelem estratos dentro da população (FONSECA; MARTINS, 1996) e há necessidade da amostra estratificada ser composta de elementos de todos os estratos (VIEIRA, 1999).

É razoável supor que variáveis apresentem um comportamento mais heterogêneo entre um estrato e outro em comparação ao comportamento dentro do mesmo estrato. Neste caso, se o sorteio dos elementos da amostra for realizado sem se considerar a existência dos estratos o resultado pode ser influenciado mais intensamente pelas características do estrato mais favorecido nos sorteios (COSTA NETO, 2002). Assim, há necessidade de calcular o tamanho da amostra de cada estrato. A forma mais simples para determinar o tamanho da amostra estratificada é aplicar ao tamanho global da amostra as percentagens que cada estrato representa na população (RICHARDSON, 1999).

\subsection{OS INSTRUMENTOS E O PREDOMÍNIO DOS QUESTIONÁRIOS}

Com relação aos instrumentos, constatou-se que $100 \%$ dos estudos quantitativos sobre o tema "características referentes aos empreendedores" utilizaram-se de questionário para coleta de dados. Conforme Marconi e Lakatos (2006), o questionário é um instrumento de coleta de dados constituído por uma série ordenada de perguntas que devem ser respondidas sem a presença do pesquisador e por escrito.

Um questionário muito longo causa fadiga e desinteresse, contudo, se curto demais, corre-se o risco de não levantar informações suficientes. Assim, deve conter entre vinte e trinta perguntas e uma necessidade de tempo para ser respondido estimado em cerca de trinta minutos, podendo este número variar conforme o tipo de pesquisa e dos informantes (MARCONI; LAKATOS, 2006). Para evitar questões supérfluas que ampliam a importunação ao pesquisado, Malhotra (2004) traz algumas informações referentes à ordem de importância das questões, podendo eliminar as que representam importância insignificante ou sejam incapazes de levantar as informações desejadas eficazmente.

Considerando que a maior parte dos questionários foi aplicada pessoalmente nos estudos avaliados, dentre as pesquisas que os encaminharam aos respondentes sem a presença de um pesquisador, apenas três especificaram a taxa de devolução, sendo 40\%, 23\% e 22\%, corroborando com as informações de Marconi e Lakatos (2006), que apontam uma média de devolução de 
Metodologia em Voga no Campo de Empreendedorismo: Emprego de Métodos Quantitativos para

O Estudo das Características Inerentes aos Empreendedores

questionários preenchidos pelos respondentes de 25\%, nos dois últimos casos e superando esta média apenas no primeiro. No caso onde houve um índice de retorno acima da média, utilizou-se a amostragem por conveniência além dos questionários terem sido distribuídos por meio de uma parceria com associações comerciais e com o Sebrae, o que pode ter influenciado no incremento do índice de retorno.Conforme Malhotra (2004), pode-se atribuir as não devoluções, em parte, à resistência das pessoas em responder determinadas perguntas. Segundo a autora, existem alguns artifícios para aumentar a disposição dos entrevistados em responder informações que não estejam dispostos a dar, colocando tópicos indiscretos ao final do questionário, apresentando as perguntas com afirmação de que o assunto é comum, formular a pergunta como se referisse a outra pessoa que não o entrevistado, não colocar perguntas de caráter delicado sequencialmente, optando por alternálas com outras de caráter neutro, entre outras técnicas que podem contribuir para um melhor índice de devolução dos questionários.

Os questionários devem ter em conta critérios de mensuração. Uma grande vantagem em mensurar dados é a possibilidade de usufruir das poderosas ferramentas da matemática no estudo de fenômenos. Para tanto, utiliza-se técnicas de escalonamento (PEDHAZUR; SCHMELKIN, 1991), atribuindo números a uma propriedade dos objetos de estudo, a fim de conferir algumas características dos números às propriedades em questão (COOPER; SCHINDLER, 2003). As escalas podem ser divididas em quatro grupos: a) nominais - nestas os respondentes colocam a si próprios ou aos indicadores de propriedades em grupos ou categorias; b) ordinais - nas quais os participantes do estudo realizam comparações entre dois ou mais indicadores ou objetos; c) intervalares - utilizam constantes unidades de mensuração proporcionando levantamentos de diferenças entre objetos, comparações de tais diferenças além de permitir a conversão de diferenças em taxas; d) escalas de razão ou proporção - as quais podem determinar um ponto zero ou absoluto. A razão, neste caso, significa que pode-se estabelecer proporções entre duas pontuações distintas independentemente da unidade empregada na escala, por exemplo, peso e altura (PEDHAZUR; SCHMELKIN, 1991). Seguindo esta classificação, as escalas mais identificadasnos estudos em questão, conforme a tabela 5, são as nominais e as de proporção, as quais refletem a sua funcionalidade para mensurar características dos indivíduos. 
Tayso Silva, Maurício Fernandes Pereira, Alexandre Marino Costa \& Cristina Hinterlang

Tabela 5 - Escalas identificadas nos artigos

\begin{tabular}{|l|c|}
\hline \multicolumn{1}{|c|}{ Escalas } & Artigos que demonstraram o emprego \\
\hline Nominais & $79 \%$ \\
\hline Proporção & $75 \%$ \\
\hline Intervalares & $57 \%$ \\
\hline Ordinais & $7 \%$ \\
\hline
\end{tabular}

Fonte: (ANPAD, on line, 2013a)

A confiabilidade relaciona-se à estimativa do grau em que uma determinada mensuração é livre de erro aleatório ou instável. Instrumentos confiáveis podem ser utilizados com a segurança de que fatores situacionais e transitórios não interferem nos resultados. O instrumento confiável assegura mensurações repetidas da mesma pessoa quando é aplicado repetidas vezes (BRYMAN, 1988), independentemente do investigador que o aplica (COOPER; SCHINDLER, 2003). Talvez, esta seja a causa principal de cientistas sociais preocuparem-se mais com a confiabilidade do que com a validade de seus estudos (BRYMAN, 1988).

A confiabilidade é um critério necessário tanto à pesquisa qualitativa quanto à quantitativa. Via de regra, quando da investigação qualitativa, a proximidade entre o pesquisador e o informante possibilita informações detalhadas; as inferências são superficiais, descrevendo-se em detalhe o correto; aplica-se o uso de gravador para registrar entrevistas e observações para análises posteriores. Na investigação quantitativa, as perguntas do questionário são formuladas clara e detalhadamente; mantém-se o anonimato do entrevistado para evitar distorções nas respostas; as definições são precisas e operacionalizam-se com indicadores específicos (RICHARDSON, 1999).

A triangulação é um procedimento que pode ser utilizado para maximizar a confiabilidade. Para tanto, quando são utilizadas mais de uma maneira de se obter dados (Entrevistas, coleta de dados secundários, questionário, observação...), possibilitam-se comparações entre os dados levantados por cada uma, realizando desta forma uma triangulação de fontes (ALVES-MAZZOTTI; GEWANDSZNAJDER, 1999). Do total de 28 artigos investigados apenas um único declarou a utilização deste procedimento.

A abordagem da consistência interna é utilizada para contribuir para com a confiabilidade da pesquisa, quando a ferramenta de mensuração apresenta muitas questões ou declarações similares. 
Metodologia em Voga no Campo de Empreendedorismo: Emprego de Métodos Quantitativos para

O Estudo das Características Inerentes aos Empreendedores

Após a administração do questionário os resultados devem ser separados por item em números pares e ímpares ou em metades selecionadas aleatoriamente. Como as duas metades apresentam um alto grau de correlação, considera-se que o instrumento possui alta confiabilidade no tocante à consistência interna dada a homogeneidade entre os itens. Entretanto, há possibilidade de inferências incorretas sobre a alta consistência interna quando o teste contém muitos itens, pois desta maneira, o índice de correlação será inflacionado (COOPER; SCHINDLER, 2003).

Existem duas principais formas de validade, a externa e a interna. A validade externa referese à capacidade dos dados de serem generalizados entre as pessoas. A validade interna limita-se ao instrumento, que só é válido quando ele é capaz de medir o que realmente é preciso medir, (BRYMAN, 1988; COOPER; SCHINDLER, 2003; RICHARDSON, 1999).O grau das diferenças encontradas com um instrumento de mensuração deve refletir as diferenças reais entre os respondentes que estão sendo testados. Para o instrumento ter validade deve ser sensível a todos os graus de significado variável e às mudanças nas nuanças de significado ao longo dos tempos (COOPER; SCHINDLER, 2003).

O procedimento mais utilizado para averiguar a validade do instrumento é o pré-teste. Testando-se os instrumentos da pesquisa sobre uma pequena parte da população do "universo" ou da amostra, antes da sua aplicação definitiva, diminuem-se as chances da pesquisa chegar a um resultado falso (MALHOTRA, 2004; MARCONI; LAKATOS, 2006). O instrumento pode ser testado, em um primeiro nível, com colegas que podem gerar diversas sugestões de melhoria ou ainda pode-se aplicar o instrumento no campo com uma amostra de respondentes ou com pessoas que apresentem características e formação similares aos respondentes desejados (COOPER; SCHINDLER, 2003). Por meio do levantamento efetuado junto aos 28 artigos quantitativos no tema “características referentes aos empreendedores" constatou-se que 28,6\% destes estudos expuseram o emprego do pré-teste em seus instrumentos de coleta de dados.

Dados dispostos em tabelas não podem ser considerados teorias. Para uma teoria poder ser considerada forte, é necessário estar amarrada a um conjunto de argumentos convincentes e logicamente interconectados. Uma teoria deve enfatizar a natureza das relações causais (SUTTON; STAW, 2003) entretanto, correlações não necessariamente implicam causa. Para se estabelecer relações causais, especificamente em estudos de recorte transversal (como é o caso dos artigos do EnAnpad investigados neste estudo), é necessário diagnosticar a dependência entre as variáveis de interesse, ou seja, certificar-se de que não são independentes entre si. Ainda, para estabelecer relações de causalidade entre as variáveis, é necessário estabelecer se a aparente relação entre duas variáveis não possui interferência de uma terceira variável que anteceda a uma ou a outra. Para 
investigar a dependência ou independência entre variáveis, pode-se recorrer a técnicas estatísticas como qui-quadrado e coeficientes de correlação (BRYMAN, 1988). A tabela 6 ranqueia os procedimentos estatísticos mais apresentados pelos artigos acerca das características referentes aos empreendedores:

Tabela 6 - Técnicas estatísticas encontradas nos artigos

\begin{tabular}{|l|c|}
\hline \multicolumn{1}{|c|}{ Técnica } & Artigos que demonstraram o emprego \\
\hline Alfa de Cronbach & $39 \%$ \\
\hline Kaiser-Meyer-Olkin & $25 \%$ \\
\hline Coeficiente de Pearson & $18 \%$ \\
\hline Qui-quadrado & $18 \%$ \\
\hline
\end{tabular}

Fonte: (ANPAD, on line, 2013a)

Além das quatro técnicas estatísticas apresentadas na tabela 6, foram utilizadas outras, em uma menor proporção, como Lambda de Wilks, Stepwise, Bartlett, Equimax, Anderson-Darling, Shapiro-Wilk, Kolmogorov-Smirnov, Split-half, Spearman-Brown, Student, Kappa, Anova e Fisher, demonstrando a ampla gama de ferramentas estatísticas à disposição para aprimoramento do tratamento dos dados quantitativos. Também se faz importante ressaltar que a maior parte (78\%) dos artigos avaliados alegou ter utilizado pelo menos um dos métodos estatísticos supramencionados. Esta taxa se eleva para $92 \%$ no caso de serem consideradas apenas as cinco edições mais recentes do evento, evidenciando a tendência para o aumento do emprego de tais técnicas estatísticas.

A abordagem quantitativa é associada com várias formas de coleta de dados. Primeiramente, a survey apresenta uma grande capacidade de levantar dados quantificáveis de pessoas que são sabidamente representativas de uma ampla população no sentido de testar hipóteses ou teorias. Tais potencialidades são entendidas por muitos pesquisadores como uma forma de captar várias informações para a ciência. A maior parte das pesquisas tipo surveybaseia-se em um projeto de pesquisa de recorte transversal, ou seja, os dados são coletados junto a pessoas em um mesmo momento no sentido de descobrir a forma e proporção pelas quais as variáveis se relacionam (BRYMAN, 1988). 
Metodologia em Voga no Campo de Empreendedorismo: Emprego de Métodos Quantitativos para

O Estudo das Características Inerentes aos Empreendedores

\subsection{OS EXPERIMENTOS PARA A COLETA DE DADOS}

A segunda forma de se coletar dados possível de ser considerada neste estudo é o experimento. Conforme Bryman (1988), enquanto a survey é a principal forma de coleta de dados em pesquisas sociológicas, o experimento é o principal meio de coleta de dados quantitativos em estudos acerca do conhecimento da área psicológica. No experimento existem, no mínimo, dois grupos (um experimental e outro de controle) formados por indivíduos aleatoriamente selecionados para os mesmos. A lógica desta modalidade consiste em submeter o grupo experimental a estímulos, que são variáveis independentes, e manter o grupo de controle livre deles. Assim, qualquer diferença observada entre os grupos é considerada decorrente das variáveis independentes contanto que os dois grupos sejam idênticos tem todos os demais aspectos. Entretanto, para Richardson (1999), especificamente nas ciências sociais, é difícil realizar uma comparação entre uma situação de controle e um tratamento. Mesmo assim, deve-se reconhecer a utilidade da ciência experimental para o desenvolvimento humano. A presença do grupo de controle, conforme Bryman (1988) caracterizam os projetos experimentais como particularmente fortes no quesito validade interna. Desta maneira, os livros sobre metodologia têm considerado os experimentos eficazes em estabelecer relações causais efetivas.

Uma completa disparidade fora encontrada por meio da avaliação da metodologia empregada nos artigos foco do presente estudo. Não houve nenhum artigo que se apresentasse enquanto experimento da maneira como exposto por Bryman (1988). Entretanto, todos eles enquadraram-se no modelo survey. Mesmo sendo experimentos e surveys provavelmente os principais veículos da pesquisa quantitativa, ainda podem ser consideradas as análises de conteúdo, a observação estruturada e a análise de dados secundários (BRYMAN, 1988). Com relação a esta última, uma fonte secundária é caracterizada por não possuir relação direta com o acontecimento registrado, entretanto, o fato de serem fontes de dados secundários não reduz a sua importância(RICHARDSON, 1999). Tal modalidade de análise de dados secundários foi encontrada consideravelmente utilizado em 14,3\% dos artigos investigados. Em apenas um dos artigos fora declarado a utilização de análise de conteúdo e em outro constava a forma observação estruturada.

Esta última pode ter sua participação ampliada se for considerado que para a eficiência de uma observação estruturada o pesquisador pode utilizar-se de formulários observacionais para especificar categoricamente informações como quem, quando, o quê, onde, por que e o modo de comportamento, passíveis de observação. Neste caso, não há necessidade da preocupação com o impacto psicológico das questões, devendo-se concentrar na elaboração de um formulário que 
identifique com clareza as informações necessárias, permita o registro preciso das informações e simplifique a codificação de entrada e análise de dados. (MALHOTRA, 2004).

\section{NOTAS FINAIS}

O presente estudo investigou a forma como a metodologia quantitativa vem sendo empregada na pesquisa sobre as características referentes aos empreendedores, mais especificamente na produção brasileira exposta no Encontro Nacional da Anpad ao longo da última década. O objetivo do presente estudo foi atingido por meio de um percurso metodológico que, após a categorização de temas abordados na pesquisa em empreendedorismo, permitiu-se encontrar a principal vertente de estudos na área, que trata das características inerentes aos empreendedores. Assim, foi possível analisar como a metodologia quantitativa tem sido empregada nestes estudos por meio da investigação dos aspectos metodológicos de cada artigo da amostra selecionada para este presente estudo.

Como principais resultados, analisou-se o uso de estratégias de pesquisa e instrumentos empregados em estudos sobre as características inerentes aos empreendedores bem como diagnosticou-se quais fatores têm sido abordados neste tema ao ser investigado no campo. Puderam ser analisados, nos estudos sobre as características inerentes aos empreendedores, o emprego de questionários, escalas, técnicas de triangulação, pré-testes, tratamentos estatísticos, abordagem paradigmática, sistemas de amostragens e, incluindo, quais são as características dos empreendedores usualmente investigadas nestes estudos apresentados na década mais recenteda história do EnANPAD.

Os resultados da pesquisa permitiram a ampliação do conhecimento científico sobre procedimentos metodológicos utilizados em pesquisas quantitativas no sentido de apresentar como os métodos quantitativos vêm sendo empregados no tema em questão. A unanimidade observada, entre as preferências dos métodos de coleta de dados no tema é o questionário. Todos os artigos avaliados o empregaram, sendo que as principais escalas de mensuração observadas nos estudos são as nominais e as proporcionais, conforme a classificação de Pedhazur e Schmelkin(1991). Tais preferências em método de coleta e mensurações refletem a natureza quantificável de características referentes aos empreendedores.

Apenas 28,6\% destes estudos expuseram o emprego do pré-teste em seus instrumentos de coleta de dados, mas apenas um declarou ter realizado triangulação. Procedimentos contributivos à 
Metodologia em Voga no Campo de Empreendedorismo: Emprego de Métodos Quantitativos para

O Estudo das Características Inerentes aos Empreendedores

validade e confiabilidade somam para a qualidade de todo e qualquer estudo empírico. Desta maneira, chama-se atenção para um fator que pode ser melhorado nas pesquisas doravante, especificamente no tema avaliado. Entretanto, Observa-se a sofisticação e riqueza em diversidade dos tratamentos estatísticos, empregados pela maior parte dos estudos, contribuindo para a importância dos mesmos para a validade e confiabilidade do conhecimento científico.

Utilizando-se da classificação paradigmática apresentada por Burrel e Morgan (1979), verificou-se que $100 \%$ dos artigos investigados foram produzidos seguindo o paradigma funcionalista.Assim, pode-se considerar, de certa forma, os benefícios da sinergia engendrada quando a maior parte dos autores seguem a mesma corrente paradigmática.Os riscos de uma impropriedade epistemológica são diminuídos quando é possível confrontar diversos conhecimentos produzidos sob uma mesma lente. Por outro lado, estudos sob a égide de outros paradigmas podem trazer importantes contribuições, como o paradigma da complexidade que, conforme Serva (1992), contém características de causalidade circular, consideração do acaso e auto-referência, demonstrando seu potencial de aplicação na análise de indivíduos, ou melhor, de características inerentes aos empreendedores.

A forma de amostragem empregada nos trabalhos foi descrita em 60,7\% dos artigos, contribuindo para a confirmação da representatividade dos estudos e, destes, 47,1\% empregaram a amostragem aleatória, 35,3\% a amostragem por conveniência e apenas 17,6\% a amostragem estratificada.

Para o campo do empreendedorismo, este levantamento demonstrou alguns temas da área que vêm sendo discutidos em uma quantidade maior de trabalhos, demonstrando que a falta de consenso sobre a delimitação do campo começa a ser resolvida quando se estabelecemum maior número de autores que têm tratado sobre um mesmo assunto. A categorização dos temas e levantamento quantitativo dos estudos sobre os mesmos, como fora exposto na tabela 3, colabora para o delineamento do escopo de pesquisa em empreendedorismo no Brasil, ajudando a esclarecer o objeto de pesquisa neste campo científico. Além disso, indicam-se aqui quais técnicas têm sido adequadas para a investigação das características inerentes aos empreendedores e apresenta-se insights para o aprimoramento das pesquisas sobre o assunto, contribuindo para o avanço dos estudos sobre empreendedorismo e sobre a administração.O nível de qualidade exigido para a publicação no EnANPAD colabora em afirmar sobre a viabilidade das estratégias de pesquisa expostas no presente estudo.

A eleição de um único tema para análise também permite o aprofundamento sobre a adequação de ferramentas de pesquisa para estudar um assunto específico. Com a utilização desta 
abordagem metodológica, pode-se observar sua aplicabilidade para investigação de diversos fatores relacionados ao tema, comopoder, ação estratégica, capacidade de persuasão, desejo de independência, autoconfiança, idade, sexo, estado civil, número de filhos, capacidade de assumir riscos, orientação para busca de oportunidade, iniciativa, capacidade de planejamento, persistência, redes de contatos, intenção empreendedora, características emocionais, atitudes, lócus de controle, experiência, missão, traços psicológicos, temperamento, pensamento analítico, variáveis culturais, potencial empreendedor, entre outros fatores referentes às características inerentes aos empreendedoresque puderam ser investigados adequadamente sob a metodologia quantitativa.

\subsection{LIMITAÇÕES E PESQUISA FUTURA}

Entre as limitações do estudo pode-se afirmar a incapacidade de abranger todos os temas de pesquisa do empreendedorismo, limitando-se às discussões sobre investigações apenas das características inerentes aos empreendedores. As estratégias empregadas nos estudos avaliados demonstraram-se viáveis nestes casos, mas não necessariamente o seriam para avaliar outros temas do empreendedorismo. Outros temas terão suas particularidades que tendem a exigir diferentes metodologias para investigação.

Da mesma forma, os achados do presente artigo refletem o emprego da metodologia quantitativa para a investigação do tema no Brasil, tendo em conta a predominância das pesquisas de campo expostas no EnANPAD serem realizadas neste país. Uma análise mais completa dos principais avanços do uso desta metodologia para a investigação deste tema do empreendedorismo demandaria a investigação de trabalhos publicados em eventos de mesma magnitude em outras regiões do globo ou ainda em periódicos internacionais, por exemplo, pelo fato de ser um tema cuja investigação é disseminada nas principais economias do planeta.

Para estudos futuros, seria interessante a replicagem desta pesquisa em outros temas do empreendedorismo ou mesmo de outras áreas da administração. Assim, seria possível fazer comparações de diferentes resultados que consideram diferentes contextos proporcionados por outras áreas contribuindo para o enriquecimento do conhecimento da pesquisa no campo da administração. A carência de estudos experimentais e longitudinais também constituem oportunidades para investigações no âmbito do empreendedorismo. Pesquisas longitudinais poderiam investigar a forma como as características referentes aos empreendedores vêm se desdobrando ao longo do tempo, de onde vieram, em termos de suas características, e para onde podem estar se direcionando. 
Metodologia em Voga no Campo de Empreendedorismo: Emprego de Métodos Quantitativos para O Estudo das Características Inerentes aos Empreendedores

Pesquisas experimentais acerca deste tema também são contributivas e poderiam acrescentar novas situações de pesquisas bastante diferentes das observadas neste momento, tendo em conta a inexistência desta modalidade de pesquisa nos trabalhos analisados.

Um estudo que contemple o "outro lado da moeda", ou seja, investigar a aplicação das pesquisas qualitativas que abordaram sobre as características inerentes aos empreendedores nestes 10 anos das categorias sobre empreendedorismo no EnANPAD também consistiria uma importante contribuição para a pesquisa em empreendedorismo e em administração.

Ainda como sugestões para estudos futuros, mais especificamente para as pesquisa acerca de características inerentes aos empreendedores, foco temático deste estudo, as diversas características observadas nos artigos do EnAnpad indicam a riqueza de variáveis consideradas para conhecimento do assunto. Entretanto, a observação funcionalista dominante na área pode ser acrescida de novas discussões. Estudos conduzidos pela lente do paradigma da complexidade poderiam ampliar o espectro de fatores que influenciam o foco do estudo, considerando que o empreendedor, ou seja, conforme Morin (1982), o homem é o ser dotado da maior complexidade existente.

Concluindo o artigo, foi possível apresentar um estudo detalhado sobre a forma como a metodologia quantitativa vem sendo empregada na pesquisa sobre o tema "características inerentes aos empreendedores". Especificamente, acerca da produção exposta no Encontro Nacional da Anpad (EnANPAD) num período de 10 anos, atingindo desta forma o objetivo aqui proposto. Foi resgatada uma categorização dos temas abordados nas pesquisas sobre empreendedorismo, transparecendo a essência do que se discute no Brasil atualmente sobre o assunto, extrapolando os limites dos estudos bibliométricos ao apresentar análises das estratégias e ferramentas de pesquisa para a investigação de um tema específico. Enfim, as ideias expostas contribuem para o fortalecimento de um importante campo científico que vem ganhando espaço cada vez mais consolidado na academia, como pode ser observado nestes 10 anos da construção do espaço próprio no maior evento científico do Brasil sobre administração. 


\section{REFERÊNCIAS}

Alves-Mazzotti, A.\& Gewandsznajder, F. O método nas ciências naturais e sociais: pesquisa quantitativa e qualitativa. 2. ed. São Paulo: Pioneira, 1999.

ANPAD. Apresentação. Disponível em: <http://www.anpad.org.br/sobre_apresentacao.php>. Acesso em: 30 julho 2012.

Associação Nacional dos Programas de Pós-Graduação em Administração. Disponível em: < http://www.anpad.org.br>. Acesso em: 22 abril2013.

. Eventos. Disponível em: <http://www.anpad.org.br/eventos.php>. Acessoem: 22abril 2013.

Becherer, R.\& Maurer, J. The proactive personality disposition and entrepreneurial behavior among small company presidents.Journal of Small Business Management. Milwaukee: v.37 n.1 p.28-36. Jan 1999.

Bruyat, C. \& Julien, P. Defining the field of research in entrepreneurship.Journal of Business Venturing, n. 16 p. 165-180, 2000.

Bryman, A.Quantity and quality in social research. London: Unwin Hyman, 1988.

Burrel, G.\& Morgan, G. Sociological paradigms and organizational analysis.London: HeinemannEducational Books, 1979.

Cooper, D.\& Schindler, P. Métodos de pesquisa em administração. $7^{\circ}$ ed. Porto Alegre: Bookman, 2003.

Costa Neto, P. Estatística. São Paulo: Edgar Blücher, 1997.

Fachin, O. Fundamentos de metodologia. 4a ed. São Paulo: Saraiva ed., 2003.

Filion, L. Le champ de l'entrepreneuriat: historique, évolution, tendances. Revueinternationale PME, v. 10 n. 2 Montreal: HEC, 36p, 1997. P. 130-172.

Fonseca, J. \& Martins, G. Curso de estatística. São Paulo: Atlas, 1996.

Gartner, W.Aconceptual framework for describing the phenomenon of new venture creation.Academy of Management Review, Vol 10, n 4, p. 696-706, 1985. 
Metodologia em Voga no Campo de Empreendedorismo: Emprego de Métodos Quantitativos para O Estudo das Características Inerentes aos Empreendedores

Gem. Global Entrepreneurship Monitor.Disponível em: <www.gemconsortium.org>. Acesso em: 03 abril 2013.

Hisrich, R.\& Peters, M. Empreendedorismo. Porto Alegre: Bookman, 2004.

Malhotra, N. Pesquisa de marketing: Orientação aplicada. $4^{\mathrm{a}}$ ed. Porto Alegre: Bookman, 2004.

MalinowskI, B. A teoria funcional. In: Uma teoria científica da cultura. Rio de Janeiro : Zahar, 1970.

Marconi, M.\& Lakatos, E. Fundamentos de metodologia científica.6 ed. São Paulo: Atlas, 2006.

Marchelli, P. \& Corcetti, E. Gestão da inovação na incubadora de base tecnológica do INATEL.In: XXVIII Encontro Nacional Da Associação Nacional Dos Programas De Pós-Graduação Em Administração, 2004, Curitiba, Anais. Curitiba, 2004.

Morin, E. Ciência com consciência. Lisboa: Europa-América, 1982.

. O Problema epistemológico da Ccomplexidade. Lisboa: Europa-América, 2002.

Pedhazur, E.\& Schmelkin, L. Measurement, design, and analysis: An integrated approach. New Jersey: LawreceErlbaum Associates Publishers, 1991.

Richardson, R. (Org.) Pesquisa social: métodos e técnicas. 3ª ed. São Paulo: Atlas, 1999.

Sarason, Y., Dean, T.\& Dillard, J. Entrepreneurship as the nexus of individual and opportunity: A structuration view. Journal of Business Venturing, v.21 n.3, p.286-305, 2006.

Sarasvathy, S. The questions we ask and the questions we care about: Reformulating some problems in entrepreneurship research. Journalof business Venturing, v.19, n.5, p.707-717, 2004.

SEBRAE. GEM 2011: Brasil é o terceiro país com o maior $\mathrm{n}^{\circ}$ de empresas. Disponível em: <www.sebrae.com.br>. Acesso em: 13 agosto 2012.

Serva, M. O paradigma da complexidade e a análise organizacional.Revista de Administração de Empresas, 32(2): 26-35, abr/jun 1992.

; Dias, T. \& Alperstedt, G. Paradigma da complexidade e teoria das organizações:Uma reflexão epistemológica. Revista de Administração de Empresas, v. 50, n. 3, jul/set. 2010.

Shane, S. A general theory of entrepreneurship: The Individual-Opportunity Nexus. NorthHampton: Edward Elgar, 2003. 
Souza, E. Empreendedorismo:Da gênesis à contemporaneidade, In: EGEPE - Encontro De Estudos Sobre Empreendedorismo E Gestão De Pequenas Empresas. 4. 2005, Curitiba, Anais... Curitiba, 2005, p. 134-146.

Sutton, R. \& Staw, B. O que não é teoria. Revista de Administração de Empresas, RAE. V. 43, n.3, 2003.

Vieira, S. Estatística para a Qualidade:Como avaliar com precisão a qualidade em produtos e serviços. Rio de Janeiro: Campus, 1999.

Welsch, H. International entrepreneurship and small business bibliography. Chicago: De Paul University, 1992.

Recebido: 16/06/2013

Aprovado: 29/08/2013 